\title{
Metaplastic carcinoma of the breast in a young female - an unusual presentation
}

\begin{abstract}
Metaplastic breast carcinoma is very rare neoplasm which contains mixture of carcinomatous and sarcomatous elements in variable proportion. We report a rare case of metaplastic carcinoma in a 34year old female, who presented with an ill-defined mass in the right breast. Fine needle aspirate smears showed pleomorphic ductal cells admixed with atypical spindle cells. Modified radical mastectomy was performed and the tumor characteristically revealed definite areas of classic infiltrating duct carcinoma and focal areas of leiomyosarcoma with giant tumor cells. Tumour cells were immunoreactive for Vimentin, ER, PR and Her2/neu. Careful gross sampling, histopathology and immunoreactivity for mesenchymal and epithelial component are most useful to differentiate metaplastic carcinoma from malignant phylloides tumors and malignant adenomyoepithelioma.
\end{abstract}

Keywords: breast, met plastic carcinoma, histopathology, Immunohistochemistry
Volume 9 Issue 4 - 2018

\author{
Kafil Akhtar, Saquib Alam, Mohd Talha, Rana K \\ Sherwani \\ Department of Pathology, Jawaharlal Nehru Medical College, \\ Aligarh Muslim University, India
}

\begin{abstract}
Correspondence: Kafil Akhtar, Department of Pathology, Jawaharlal Nehru Medical College, Aligarh Muslim University, Aligarh (UP), India, Email drkafilakhtar@gmail.com
\end{abstract}

Received: July 30, 2018 | Published: August 09, 2018

\section{Introduction}

Metaplastic carcinoma of the breast is a rare heterogenousmalignant tumorcomprising of ductal, squamous and/or mesenchymaltissues.1 It is generally characterized by a mixture of intraductal or infiltrating carcinoma and foci of carcinoma with extensive metaplastic differentiation to squamous, spindle cells and heterologous mesenchymalelements. ${ }^{1}$

Metaplastic carcinoma of the breast accounts for $0.2 \%$ of all breast cancers. ${ }^{2}$ Varied forms of metaplastic carcinomas aresarcomatoidcarcinoma or carcinosarcoma, spindle cell carcinoma, carcinoma with osteoclast like giant cells and squamous cellcarcinoma. We report this case because of its rarity and diagnostic dilemma, if thetumor is composed predominantly of sarcomatouscomponents.

\section{Case summary}

Afemale aged 34years presented to the Surgical Clinics with ulcerated mass in the right breast for 5months. On examination, a breast mass of $9 \times 8 \mathrm{~cm}$ in size was seen in the right upper quadrant, with an overlying ulceration on the skin surface. The swelling was hard in consistency, with well-defined margins and fixed to the underlying tissue and the skin. Multiple enlarged mobile lymph nodes were noted in the right axilla. General and systemic examination of the patient were normal. A clinical diagnosis of breast malignancy was made.

Fine needle aspiration cytology of the mass was performed, which revealed cohesive clusters of pleomorphic ductal cells with marked anisonucleosis andhyperchromaticnuclei with indistinct nucleoli. A cytological diagnosis suggestive ofbreastcarcinoma was given. The patient underwent simple mastectomy with axillary lymph node dissection. Gross examination of specimen revealed a greyish white, irregular, hard growth of $4 \times 2 \mathrm{~cm}$ in the upper outerquadrant of the breast. Microscopic examination of the sections from the growthshowedatypical tumorcells in nests and cords and singly arranged with areas oftumor cells depictingsarcomatousmorphology resembling malignant fibrous histiocytomawith scattered mononuclear and bizarre tumor cells (Figures 1), (Figure 2). Manyabnormal mitosis were also seenwithextensive areas of necrosis and moderate desmoplasia.On immunohistochemistry, the tumour cells were immunoreactive for Vimentin (Figure 3), ER, PR and Her2/neu. The adjoining breast tissueshowed fibrocystic change. All surgical resection margins, nipple andareola and sampled lymph nodes were not involved by thetumorcells. Based on theimmune-histological features, a diagnosis of Metaplastic Carcinoma with high grade spindle cell component was given. Adjuvant 6 cycles of taxane based chemotherapy was administered. Our patient died after 12 months of follow up.

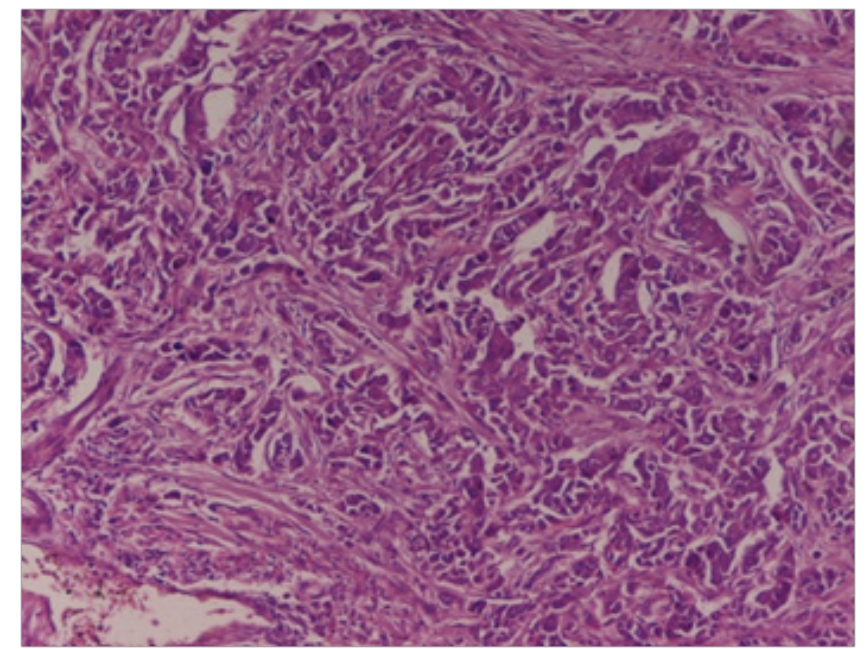

Figure I The atypical tumor cells formed nests and cords with areas oftumor cells depictingsarcomatousmorphology resembling malignant fibrous histiocytoma with scattered mononuclear and bizarre tumor. Hematoxylin and Eosinx 10X. 


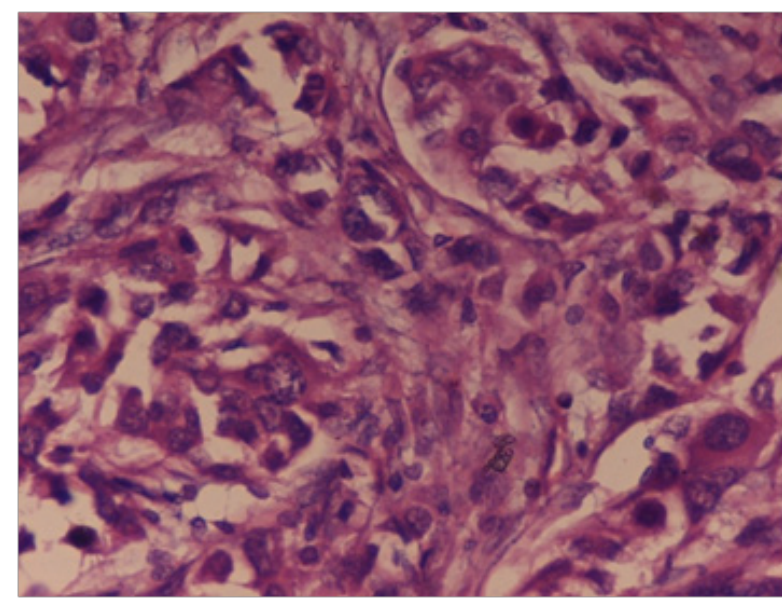

Figure 2 High power of Figure I.

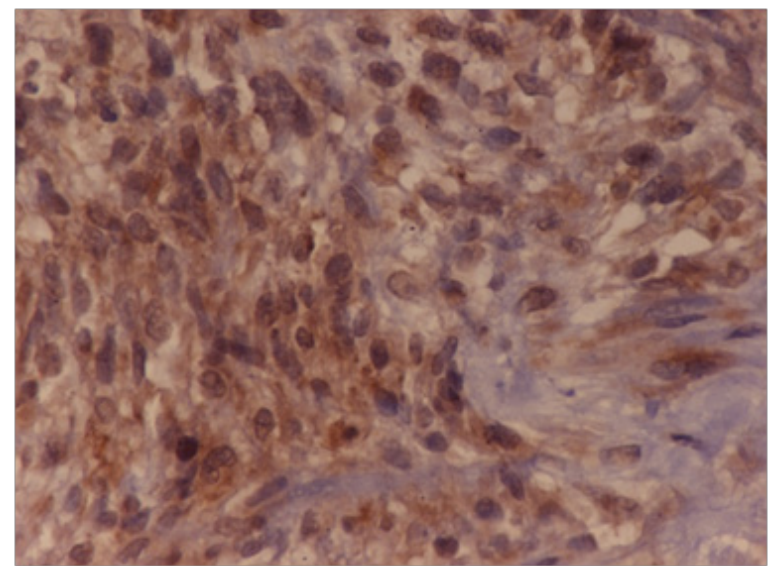

Figure 3 On immunohistochemistry, the tumour cells showed cytoplasmicimmunoreactivity for Vimentin. IHC Vimentinx40X.

\section{Discussion}

Metaplastic carcinoma is an uncommontumor of the breast, which consists of infiltrating ductal carcinoma contiguous or subtly merged with highly cellular, mitotically active pleomorphic and bizarre spindle cells..$^{3,4}$ Metaplastic breast carcinoma is very rare neoplasm of high-grade nature.

Breast carcinomas showing extensive metaplastic change to squamous cells, spindle cells and heterologous mesenchymal elements are well recognized. ${ }^{5,6}$ The diagnosis of metaplastic carcinoma is difficult to establish,byclinico-pathological examination. ${ }^{2}$ However, in most tumors, small foci of infiltrating ductal carcinoma are present with transition to metaplastic elements. Our case showed varying proportions of carcinomatous and pseudosarcomatous elements in a desmoplastic stroma.The usual sarcoma like elements may resemble malignant fibrous histiocytoma, chondrosarcoma, osteosarcoma, rhabdomyosarcoma or a combination of these. ${ }^{4}$ In the present case, the sarcomatous element resembled malignant fibrous histocytoma with presence of bizarre giant cells; very similar to the findings of Bilgen et al. ${ }^{7}$

Most metaplastic carcinomas are sporadic. But metaplastic spindle cell carcinoma are known to arise from pre-existing lesions, including papillomasand complex sclerosingadenomas. ${ }^{8,9}$ Metaplastic or spindle cell carcinomas arising from such lesions can show a varying degree of malignancy, ranging from low to high grade. ${ }^{10}$ This type of lesion should also be differentiated from the so-called reactive spindle cell nodule, which is believed to be benign and may also complicate preexisting lesions such as papillomas or complex sclerosing lesions. ${ }^{11}$

Metaplastic carcinoma is probably derived from myoepithelial cells. Thesemyoepithelial cell have the propensity todifferentiate into epithelial as well as mesenchymal elements. ${ }^{5}$ The incidence of lymph nodal metastasis from metaplastic carcinoma is lower than the usual infiltrating duct carcinoma, as was seen in our case. Purely spindled/ sarcomatoid tumors have significant lower rate of nodal metastasis than conventional ductal and lobular carcinomas.6The reported case differs from the previous case reports by Joshiet al, is that it did not show any malignant squamous differentiation. ${ }^{2}$

An aggressive course has been seen in metaplastic carcinomassarcomatoid type as compared to the matrix producing metaplastic carcinomas, which have a favourable course. ${ }^{12}$ Most metaplasticcarcirnomas are negative for ER and PR \& HER2/neu and are managed by radical mastectomy followed by radiation and chemotherapy. ${ }^{12}$ Our patient was administered 6 cycles of taxane based adjuvant chemotherapy, but she died after 12 months of follow up.

Immunohistochemistry plays a major role in the evaluation of tumors that lack clear cut evidence of carcinoma. The sarcoma like elements of these tumors are usuallyvimentinand S-100 positive, but occasional focal cytokeratin positive epithelial tumor cellsmay be seen. ${ }^{13,14}$ The combined use of AE1/AE3 and CAM $5 .{ }^{2}$ Shows a higher sensitivity than each marker alone. ${ }^{15}$

The presence of biphasic tumor cells; atypical spindle cells admixed with poorly differentiated carcinoma cells and squamous carcinoma cells with giant cells may provide clues for the fine needle aspiration diagnosis of metaplastic carcinomas. 2 When a pathologist encounters a breast tumor with sarcomatous differentiation, careful gross sampling, histopathology and immunoreactivity for mesenchymal and epithelial component should be performed to differentiate metaplastic carcinoma from malignant phylloides tumors and malignant adenomyoepithelioma. ${ }^{4}$

\section{Acknowledgements}

None.

\section{Conflict of interest}

The author declares no conflict of interest.

\section{References}

1. Rosen PP. Carcinoma with metaplasia. In Rosen PP, editor. Rosens Breast Pathology. 3rd. ed. Philadelphia: Lippincott Williams and Wilkins; 2009. p. $425-452$.

2. Joshi D, Singh P, Zonunfawni Y, et al. Metaplastic carcinoma of the breast: cytological diagnosis and diagnostic pitfalls. ActaCytologica. 2011;55(4):313-318.

3. Al Sayed AD, El Weshi AN, Tulbah AM, et al. Metaplastic carcinoma of the breast. Clinical presentation, treatment results and prognostic factors. Acta Oncol. 2006;45(2):188-195. 
4. Nikumbh DB, Jagtap SV, Kanetkar SR. Metaplastic carcinoma of the left breast with extensive chondroid differentiation. Annals Pathol Lab Med. 2011;23:23-26.

5. Lui PCW, Tse GMK, Tan PH. Fine-needle aspiration cytology of metaplastic carcinoma of the breast. J Clin Pathol. 2007;60(5):529-533.

6. Park SP, Park S, Kim JH. Clinicopathologic features and outcomes of metaplastic breast carcinoma: comparison with invasive ductal carcinoma of the breast. Yonsei Med J. 2010;51(6):864-869.

7. Bilgen G, Memi A, Ustun EE, et al. Metaplastic carcinoma of the breast: clinical, mammographic, and sonographic findings with histopathologic correlation. Am J Roentgenol. 2002;178(6):1421-1425.

8. Tse GM, Tan PH, Putti TC, et al. Metaplastic carcinoma of the breast: a clinicopathological review. J Clin Pathol. 2006;59(10):1079-1083.

9. Koker MM, Kleer CG. p63 expression in breast cancer: a highly sensitive and specific marker of metaplastic carcinoma. Am J Surg Pathol. 2004;28(11):1506-1512.
10. Leibl S, Moinfar F. Metaplastic breast carcinomas are negative for Her-2 but frequently express EGFR (Her-1): potential relevance to adjuvant treatment with EGFR tyrosine kinase inhibitors? J Clin Pathol. 2005;58(7):700-704.

11. Jayaram G, Sthaneshwar P. Fine-needle aspiration cytology of phyllodes tumors. Diagn Cytopathol. 2002;26(4):222-227.

12. Mardi K, Sharma J. Matrix-producing mammary carcinoma: a rare breast tumor. Indian J Pathol Microbiol. 2008;51(2):263-264.

13. $\mathrm{Ng} \mathrm{WK}$. Fine needle aspiration cytology of fibroadenoma with multinucleated stromal giant cells. A review of cases in a six-year period. Acta Cytol. 2002;46(3):535-539.

14. Hee JS, Hak HK, Sun MK. Imaging features of metaplastic carcinoma with chondroid differentiation of the breast. AJR. 2007;188(3):691-696.

15. Dunne B, Lee AH, Pinder SE. An immunohistochemical study of metaplastic spindle cell carcinoma, phyllodes tumour and fibromatosis of breast. Hum Pathology. 2003;34(10):1009-1015. 